\title{
Proactive parenting practices during early adolescence: A cluster approach
}

Laura M. Padilla-Walker

Brigham Young University, laura_walker@byu.edu

Katherine J. Christensen

Randal D. Day

Follow this and additional works at: https://scholarsarchive.byu.edu/facpub

Part of the Social and Behavioral Sciences Commons

\section{Original Publication Citation}

Padilla-Walker, L. M., *Christensen, K. J., \& Day, R. D. (2011). Proactive parenting practices during early adolescence: A cluster approach. Journal of Adolescence, 34, 203-214.

\section{BYU ScholarsArchive Citation}

Padilla-Walker, Laura M.; Christensen, Katherine J.; and Day, Randal D., "Proactive parenting practices during early adolescence: A cluster approach" (2010). Faculty Publications. 4927.

https://scholarsarchive.byu.edu/facpub/4927 


\title{
Proactive parenting practices during early adolescence: A cluster approach
}

\author{
Laura M. Padilla-Walker*, Katherine J. Christensen, Randal D. Day \\ Brigham Young University, Provo, UT 84602, United States
}

\section{Keywords:}

Proactive parenting

Parenting practices

Early adolescence

Cluster analysis

\begin{abstract}
A B S T R A C T
The purpose of the current study was to explore clusters of proactive parenting practices, and how they might vary as a function of parental demographics, the quality of the parentchild relationship, and the traits and behaviors of the adolescent child. Data were taken from the Flourishing Families Project, which includes 500 families with an early adolescent child ( $M$ age $=11.49$ ). Findings suggested that there were four clusters of parents, and patterns were similar for mothers and fathers. Findings also suggested that proactive clusters varied primarily as a function of demographics of the parent (e.g., religiosity, ethnicity, education) and the traits and behaviors of the adolescent child (e.g., empathy, internalizing and externalizing behaviors). Discussion highlights the importance of using a typological approach to study parenting, and places particular emphasis on parents' use of pre-arming (alone, or in conjunction with other practices) in an attempt to avoid misbehavior before it occurs.

(c) 2010 The Association for Professionals in Services for Adolescents. Published by Elsevier Ltd. All rights reserved.
\end{abstract}

Most scholars agree that parents play a significant role in the socialization of adolescents, but parenting is often conceptualized in a variety of different ways, with a variety of different outcomes. In an attempt to better organize the broad concept of parenting, Darling and Steinberg (1993) suggested an important distinction between parenting styles and parenting practices. More specifically, parenting styles are indicative of the overarching emotional climate that the parent creates for socialization, while parenting practices are intentional parental behaviors in response to specific socialization goals. While parenting styles (also referred to as indirect parental influences; Ladd \& Pettit, 2002) impact the adolescent's willingness to comply; parenting practices (also referred to as direct parental influences) generally have a direct impact on adolescents' behavior. This distinction between parenting styles and practices (or between indirect and direct parenting) has been an important framework for the last decade of research that has greatly expanded our understanding of the parent-child relationship. For example, a great deal is known about various parenting practices such as induction and power assertion, and how indirect parental influences moderate the relation between practices and child outcomes (e.g., Kochanska, Aksan, Knaack, \& Rhines, 2004; Mounts, 2002). However, the largest body of research on direct parenting practices has focused on reactive parenting practices, or parental responses after the child transgresses (for reviews, see Eisenberg \& Fabes, 1998; Grusec, 2002; Maccoby, 2007). In contrast, proactive parenting practices, or parenting that involves anticipatory rather than reactive techniques, is less prominent and lacks a unified definition of what constitutes "proactive" parenting. Thus, the purpose of the current study was to examine typologies or clusters of different parental approaches to proactive parenting, and to explore correlates of these typologies.

\footnotetext{
* Corresponding author. 2097 JFSB, School of Family Life, Brigham Young University, Provo, UT 84602, United States. Tel.: +1 801422 9053; fax: +1801 4220230.

E-mail address: laura_walker@byu.edu (L.M. Padilla-Walker).
} 


\section{Proactive parenting practices}

It should be noted that much of the socialization literature contains parenting practices that could be considered proactive, such as parental support, praise, monitoring, and involvement. Indeed, reactive parenting is also somewhat proactive in nature, as parents often discipline in an attempt to avoid future misbehavior. However, few studies have purposively separated proactive and reactive parenting practices, and even fewer have examined proactive parenting practices during adolescence. Developmentally, proactive practices during childhood look much different than during adolescence, and are likely motivated by different parental goals. Indeed, proactive attempts during childhood may be motivated by parents' desires to avoid specific instances of misbehavior (e.g., tantrum in the grocery store), while proactive practices during late childhood and early adolescence are more likely motivated by parents' attempts to pre-empt potentially conflicting values messages or influences that become more prominent during adolescence (Padilla-Walker, 2006; Padilla-Walker \& Thompson, 2005). This approach to parenting takes place prior to misbehavior, which is unique in that it is not accompanied by the heightened emotional response that often coincides with a child's transgression.

Holden (1983) explained proactive parenting as using preventative control techniques, such as those highlighted in his study on mothers who anticipated and directed the development of their children by preventing misbehavior in the supermarket. Since Holden's introduction to proactive parenting, research on this topic has been characterized by three main uses of the term "proactive". The first is among studies of minority parents who teach positive racial socialization messages and important life skills in anticipation of discrimination (Barr \& Neville, 2008; Letiecq, 2007). The second conceptualizes parental monitoring as a proactive parenting practice because parents are actively seeking knowledge about their child in an effort to prevent misbehavior (Kosterman, Hawkins, Guo, Catalano, \& Abbott, 2000; Lansford et al., 2006). The third most closely resembles Holden's definition and captures the active and anticipatory process of parents to head off problems before they occur. These studies describe, as a part of this preventative process, teaching, involvement, prohibition, and redirecting of attention (Gardner, Ward, Burton, \& Wilson, 2003; Mounts, 2002; Nikken \& Jansz, 2006; Pettit, Laird, Dodge, Bates, \& Criss, 2001; Putnam, Spritz, \& Stifter, 2002).

Regardless of the definitions used for proactive parenting, results have linked proactive parenting practices with improved outcomes for children. Proactive parenting is associated with fewer conduct and behavior problems (Gardner, Shaw, Dishion, Burton, \& Supplee, 2007; Pettit, Keiley, Laird, Bates, \& Dodge, 2007), delay of alcohol and drug use (Hawkins et al., 1997; Kosterman et al., 2000), and improved delay of gratification in children (Putnam et al., 2002). However, these results are largely found in studies examining young children (Gardner et al., 2007; Holden \& West, 1989), with far fewer studies looking at the influence of proactive parenting practices during adolescence (with the exception of parents' mediation of media and management of peers). In addition, few scholars have distinguished between different proactive parenting practices and their associated benefits for children and adolescents. Thus, the purpose of the current study was to examine parents' patterns of proactive parenting practices (using a cluster analysis approach), and how these combinations of proactive parenting were related to demographics of the parent, the quality of the parent-child relationship, and traits and behaviors of the adolescent child.

\section{Specific proactive parenting practices}

Goodnow (1997, 2002) suggested two specific proactive approaches parents might use to combat potentially conflicting values messages in order to prevent misbehavior. The first is cocooning, in which parents seek to shelter their child from outside influences. Cocooning, as described by Padilla-Walker and Thompson (2005), is the most controlling proactive parenting practice, as parents actively seek to align exterior influences on children with their personal values or wishes. Other researchers have found support for this parenting practice, although it may not have been labeled as such. For example, Letiecq (2007) described African American parents' attempts to reduce outside influence in the home by restricting violent media, and Mounts (2002) assessed parents' prohibition of undesired friendships in her work on parental management of peer relationships.

Another proactive parenting practice is pre-arming (Bugental \& Goodnow, 1998), where parents provide the child with some plan, or "advance arming" to face the outside world (p. 434), thus anticipating potential problems for the child and preparing them to meet this opposition with success. This socialization tactic has been effective for minority parents in preparing their children to successfully manage racial stereotypes and hostility faced outside the home (Barr \& Neville, 2008; Harrison, Wilson, Pine, Chan, \& Buriel, 1990), and has been linked to lower levels of association with deviant peers (Mounts, 2002).

In addition to cocooning and pre-arming, studies have identified another proactive parenting practice termed deference (Padilla-Walker, 2006; Padilla-Walker \& Thompson, 2005). Deference is a proactive strategy with high levels of autonomy, in which parents purposefully allow their child to be exposed to outside influences with little advanced teaching or ammunition. Parental deference is often discussed by parents as an active attempt to show trust and to avoid overreacting and alienating their child, or to prevent conflict (Padilla-Walker, 2006). Denham et al. (2000) explained that parents sometimes choose not to intervene in child decision making with the explanation, "I trust my child to behave as he should, even when I am not with him" (p. 30). The parental justification in this instance often centers on having already taught the child the relevant values, and now represents the parents' attempt to provide autonomy. Taken together, different names and labels have been used to 
examine proactive parenting practices in previous research, but the current labels provide a clear framework for examining and understanding proactive strategies employed by parents.

\section{Current study: a cluster analysis approach}

Research on reactive parenting suggests that parents do not use only one parenting practice, but rather, use flexibility in parenting as a function of the child's misdeed, and often use a combination of practices, such as power assertion and induction (Grusec \& Goodnow, 1994; Grusec \& Kuczynski, 1980). Indeed, both conceptually and statistically, a typological approach to parenting more accurately captures reality and increases the power of the analysis (Darling \& Cumsille, 2003). Thus, although it is likely that parents use a combination of proactive parenting practices to meet their goals, it is yet unclear how these practices might combine and how effective different combinations might be in promoting parents' socialization goals. Thus, the purpose of the current study was two-fold. First, using cluster analysis we attempted to more accurately capture the proactive environment by examining whether there were different clusters of parents who might use one or more proactive parenting practices. Second, in an attempt to understand which practices might be most effective, the current study examined how the clusters that emerged differed as a function of demographics of the parent (i.e., ethnicity, family structure, education, and religiosity), the quality of the parent-child relationship (i.e., attachment, connectedness, involvement, and knowledge), and the traits and behaviors of the adolescent child (i.e., age, gender, empathy, self-regulation, internalizing behavior and externalizing behavior). While we had no a priori hypotheses about the proactive parenting clusters that might emerge, basic components of each practice provide insight into how they might vary in these three areas.

\section{Demographics of the parent}

First, given previous research indicating that proactive parenting practices vary as a function of parental cognitions and religiosity (Padilla-Walker, 2006; Padilla-Walker \& Thompson, 2005), as well as research suggesting that other parenting practices vary as a function of ethnicity (Coll \& Pachter, 2002), family structure (Weinraub, Horvath, \& Gringlas, 2002), and SES (Conger \& Donnellan, 2007), we hypothesized that proactive clusters would vary as a function of parental demographic variables. Given research suggesting that lower SES individuals use more controlling forms of parenting (Conger \& Donnellan, 2007), we thought it possible that strategies involving cocooning would be more common among single parents, low income parents, and parents with lower levels of education. Research has also suggested that pre-arming and cocooning are more often used when parents feel their values are threatened (e.g., minority parents who feel discriminated against, or religious parents; Padilla-Walker \& Thompson, 2005), so we also expected that strategies involving cocooning and pre-arming might be more common for minority parents and parents who were highly religious.

\section{Quality of the parent-child relationship}

Second, in regard to the quality of the parent-child relationship, we examined aspects of parenting that were indicative of both indirect (e.g., connectedness, attachment) as well as direct (e.g., knowledge, involvement) aspects of parenting in order to gain a greater understanding of how different proactive parenting practices might be related to other well-established aspects of parenting. Given research suggesting the importance of parents' use of induction (Krevans \& Gibbs, 1996), we thought it likely that clusters including pre-arming (the proactive parenting strategy with the most parent-child communication) would be more consistently associated with positive parenting. We also explored, given the age of the adolescents, whether deference was associated with positive aspects of parenting that would be indicative of deference as a form of autonomy granting, or whether it was more indicative of permissiveness when used this early in adolescence.

\section{Traits and behaviors of the child}

Finally, because we are aware of no existing studies that have looked at the differential effectiveness of specific proactive parenting practices, we examined relations between proactive parenting and child traits and behaviors. Given research suggesting variations in parenting practices as a function of the age of the child (e.g., Steinberg \& Silk, 2002), we expected that parents may use more controlling proactive parenting practices with younger adolescents. In addition, we sought to examine both positive and negative child outcomes related to proactive parenting, so we examined both dispositional traits (i.e., empathy, self-regulation) as well as behaviors (i.e., internalizing, externalizing) that have been found to be central to healthy adjustment during adolescence (Eisenberg \& Fabes, 1998; Farrington, 2004; Graber, 2004). Based on the extreme level of control, or lack of control, proactive practices using predominantly cocooning or deference were expected to be related to less positive outcomes than other strategies. Due to the communication inherent in pre-arming (as with reactive induction), we expected that proactive parenting approaches using pre-arming would be more consistently related to positive child outcomes (Kerr, Lopez, Olson, \& Sameroff, 2004; Krevans \& Gibbs, 1996). 


\section{Method}

\section{Participants}

The participants for this study were taken from Wave 1 of the Flourishing Families Project (FFP). The FFP is a longitudinal study of inner family life involving families with a child between the ages of 10 and 14 at Wave 1 . This study consisted of 500 families (164 single-parent, 336 two-parent) with a child between the ages of 11 and 14 ( $M$ age of child = 11.49; 51\% male). Ninety-three percent of mothers and $90 \%$ of fathers reported being biological parents, $5 \%$ reported being adoptive parents, and $2 \%$ of mothers and $5 \%$ of fathers reported being step-parents. Seventy-six percent of mothers, $86 \%$ of fathers, and $70 \%$ of children were European American; $13 \%$ of mothers, $6 \%$ of fathers, and 13\% of children were African American; $3 \%$ of mothers, $2 \%$ of fathers, and $5 \%$ of children were Asian American; 2\% of mothers, $1 \%$ of fathers, and $2 \%$ of children were Hispanic; and 3\% of mothers and fathers, and $11 \%$ of children indicated that they were "mixed/biracial" or of another ethnicity. Fourteen percent of families reported an income less than $\$ 25,000$ per year, $16 \%$ made between $\$ 25,000$ and $\$ 50,000$ a year, and $70 \%$ made more than $\$ 50,000$ per year. In terms of education, $60 \%$ of mothers and $70 \%$ of fathers reported having a bachelor's degree or higher.

\section{Procedure}

Participant families for the FFP were selected from a large northwestern city and were interviewed during the first eight months of 2007. Families were primarily recruited using a purchased national telephone survey database (Polk Directories/ InfoUSA). This database claimed to contain 82 million households across the United States and had detailed information about each household, including presence and age of children. Families identified using the Polk Directory were randomly selected from targeted census tracts that mirrored the socio-economic and racial stratification of reports of local school districts. All families with a child between the ages of 10 and 14 living within target census tracts were deemed eligible to participate in the FFP. Of the 692 eligible families contacted, 423 agreed to participate, resulting in a $61 \%$ response rate. However, the Polk Directory national database was generated using telephone, magazine, and Internet subscription reports; so families of lower socio-economic status were under-represented. Therefore, in an attempt to more closely mirror the demographics of the local area, a limited number of families were recruited into the study through other means (e.g., referral, fliers; $n=77,15 \%$ ). By broadening our approach, we were able to significantly increase the social-economic and ethnic diversity of the sample.

All families were contacted directly using a multi-stage recruitment protocol. First, a letter of introduction was sent to potentially eligible families (this step was skipped for the 15 families who responded to fliers). Second, interviewers made home visits and phone calls to confirm eligibility and willingness to participate in the study. Once eligibility and consent were established, interviewers made an appointment to come to the family's home to conduct an assessment interview that included video-taped interactions (not used in current study), as well as questionnaires that were completed in the home (participants were encouraged to complete questionnaires in separate rooms and not to discuss answers during administration). The most frequent reasons cited by families for not wanting to participate in the study were lack of time and concerns about privacy. It is important to note that there were very little missing data. As interviewers collected each segment of the inhome interview, questionnaires were screened for missing answers and double marking.

\section{Measures}

\section{Proactive parenting}

Parents responded to eight items on a 5-point Likert scale ranging from 1 (never) to 5 (very often) to assess three types of proactive parenting practices found in previous studies: cocooning, pre-arming, and deference (Padilla-Walker, 2006; PadillaWalker \& Thompson, 2005). Parents were asked to think of how frequently they use a variety of intentional and active approaches to socialize their children before transgression has occurred. Items assessed cocooning (two items; "I do not allow my child to be with friends who behave in ways I disapprove of" and "I do not allow my child to watch television programs I disapprove of"), pre-arming (three items; "I talk to my child about how to avoid Internet content that I might disapprove of," "I talk to my child about what to do when she/he sees something on television I might disapprove of," and "I talk to my child about how to stand up for what she/he believes when she/he has friends who behave in ways I might disapprove of") and deference (three items; "I do not limit what my child watches on television," "I do not limit the friends my child associates with," and "I do not limit my child's exposure to the Internet").

Exploratory factor analysis using varimax rotation was used (separately for mothers and fathers) to confirm that the items held together as three separate constructs. For mothers, analyses found three factors with Eigen values above a 1.0, with a cocooning factor (11\% of the variance, 2 items with factor loadings of .51 and $.69, \alpha=.40$ ), a pre-arming factor (15\% of the variance, 3 items with factor loadings of .84, .80, and .75, $\alpha=.72$ ), and a deference factor (25\% of the variance, 3 items with factor loadings of $.69, .79$., and $.83, \alpha=.72$ ). For fathers, analyses found three factors with Eigen values above a 1.0 , with a cocooning factor ( $10 \%$ of the variance, 2 items with factor loadings of .49 and $.76, \alpha=.40)$, a pre-arming factor (24\% of the variance, 3 items with factor loadings of .76, .76, and .75, $\alpha=.70)$, and a deference factor (15\% of the variance, 3 items with factor loadings of .72, .77., and .79, $\alpha=.69)$. Items loading on similar factors were the same for mothers and fathers, thus items 
within each factor were summed to create frequency of proactive parenting strategies for both mothers and fathers, with higher scores representing higher levels of cocooning, pre-arming, and deference.

\section{Demographics of the parent}

To assess how demographics of the parent varied as a function of clusters of proactive parenting, we measured family structure (single vs. two-parent), parent ethnicity (European American, African American, and mixed/other), education, and religiosity. To assess education, parents were asked for their highest level of completed education. Religiosity was measured using four items from the Santa Clara Strength of Religious Faith Questionnaire (Lewis, Shevlin, McGuckin, \& Navrtil, 2001). Parents responded on a 4-point Likert scale ranging from 1 (strongly disagree) to 4 (strongly agree) (e.g., "I pray daily," and "My faith impacts many of my decisions"). Items were averaged with higher scores indicating higher religious faith. Cronbach's alpha in the current study was .95 for mothers and .96 for fathers.

\section{Quality of the parent-child relationship}

To assess how the quality of the parent-child relationship varied as a function of clusters of proactive parenting, we measured parental attachment, parent-child connectedness, parental involvement, and parental knowledge.

Parent-child attachment was measured using 8 items from the trust subscale of the Inventory of Parent and Peer Attachment (Armsden \& Greenberg, 1987). Questions focused on perceived communication with, trust in, and alienation from parent(s). Sample items include, "My parent respects my feelings," and "My parent trusts my judgment." Adolescents answered separately for mothers and fathers on a 5-point Likert scale ranging from 1 (strongly disagree) to 5 (strongly agree). Items were averaged and higher scores indicated higher parent-child attachment ( $\alpha=.71$ for mothers, .74 for fathers).

The degree to which parents felt connected to the target child was assessed using 9 items from the Social Connectedness Scale (Lee, Draper, \& Lee, 2001). Parents responded on a 6-point Likert scale from 1 (disagree) to 6 (agree), and were asked to respond in terms of their agreement or disagreement with statements such as, "I feel distant from my child," and "I feel understood by my child." Negative items were recoded and items were averaged, with higher scores representing higher feelings of parent-child connectedness ( $\alpha=.85$ for mothers, .88 for fathers).

Level of parental involvement was measured using an 8-item modified version of the Inventory for Father Involvement (Hawkins et al., 2002). Adolescents answered items separately in relation to maternal and paternal involvement on a 5-point Likert scale ranging from 1 (never) to 5 (very often), with sample items such as "How often does your mother/father give you encouragement" and "How often does your mother/father help you with homework". Items were averaged, with higher scores indicating higher levels of parental involvement ( $\alpha=.77$ for mothers, .82 for fathers).

Parental knowledge, or parents' awareness of their child's activities and behaviors, was assessed using a 4-item Parental Knowledge measure (Kerr \& Stattin, 2000). Parents responded on a 5-point Likert scale ranging from 1 (never) to 5 (always). Sample questions include, "When my child is not at home, I know where s/he is," and "I know who my child's friends are." Items were averaged, with higher scores indicating more knowledge about the child's behavior $(\alpha=.69$ for mother, .72 for father).

\section{Traits and behaviors of the child}

To assess how traits and behaviors of the child varied as a function of clusters of proactive parenting, we measured children's age, empathy, self-regulation, and internalizing and externalizing behaviors.

Empathic concern was assessed from mother-reports of their child's empathy (Davis, 1983). Mothers answered 7 items on a 5-point Likert scale, with responses ranging from 1 (strongly disagree) to 5 (strongly agree). Sample items include, "When my child sees someone being taken advantage of, she/he feels kind of protective towards them," and "My child is often quite touched by things that she/he sees happen." Items were averaged with higher scores indicating higher levels of empathy $(\alpha=.81)$.

Cognitive self-regulation was assessed via the child's report of his/her own self-regulation (Novak \& Clayton, 2001). Adolescents responded to 4 items on a 5-point Likert scale ranging from 1 (never true) to 5 (always true). Sample items include, "I develop a plan for my important goals" and "I think about the future consequences of my actions." Items were averaged and higher scores represent higher levels of self-regulation $(\alpha=.80)$.

Internalizing and externalizing behaviors were measured using items assessing antisocial behavior (9 items) and depression/anxiety (13 items), which have shown adequate reliability in adolescent samples (Barber, Stolz, Olsen, \& Maughn, 2005). Sample items for internalizing include "I feel that no one loves me," and "I feel lonely"; and sample items for externalizing include "I lie or cheat," and "I steal things from other places than home". Items were averaged on a scale ranging from 0 (not true) to 2 (very true or often true), with higher scores representing higher levels of internalizing $(\alpha=.86)$ and externalizing $(\alpha=.71)$ behaviors.

\section{Results}

\section{Descriptive statistics and correlations}

A number of $t$-tests were conducted to determine if levels of the individual proactive parenting practices differed as a function of gender of the parent. Results suggested that there were no mean differences between mothers $(M=3.11$, 
$S D=.89)$ and fathers $(M=3.05, S D=.88)$ for cocooning. However, mothers $(M=4.25, S D=.77)$ reported higher levels of prearming than did fathers $(M=4.00, S D=.81)$, and fathers $(M=2.12, S D=.93)$ reported higher levels of deference than did mothers $(M=1.89, S D=.89)$. We also conducted a number of ANOVAs and chi-square analyses to determine if variables of interest varied as a function of recruitment protocol (randomly selected vs. other), and the only differences were that those who were not randomly selected were more likely to be African American and single parents than were those who were randomly selected, which was expected given our targeted attempt to increase the ethnic diversity of the sample.

Correlations between all study variables are presented in Table 1. In general, for both mothers and fathers, cocooning was negatively related to parental education and age of the child, and positively related to religiosity, parental involvement and knowledge, and the child's self-regulation. Pre-arming was positively related to parents' religiosity, attachment, connectedness, involvement, knowledge, and the child's empathy and self-regulation; and negatively to children's internalizing behavior. Deference was negatively related to parental religiosity, involvement, knowledge, and child's empathy; and positively related to child's age and externalizing behavior (although only the correlation between deference and religiosity was statistically significant for fathers).

\section{Cluster analysis}

Ward's hierarchical clustering procedure was conducted on the three proactive parenting practices (cocooning, prearming, and deference), separately for mothers and fathers. Using the hierarchical approach in an attempt to maximize the differences between clusters, we determined the number of clusters by treating each parent as a separate cluster and then combining the most similar parents systematically until there was one, all-inclusive cluster (Ward, 1963). In order to determine the number of clusters, first we examined hierarchical dendrogram and agglomeration coefficients (Bergman, Magnusson, \& El-Khouri, 2003). Dendrograms revealed that there were between 3 and 5 clusters for both mothers and fathers. When examining agglomeration coefficients, the number of clusters is determined based on the relative stability in change in the agglomeration coefficient from one stage to the next (Hair, Anderson, Tatham, \& Black, 1998). This examination supported a 4-cluster solution for both mothers and fathers. In addition, Milligan and Cooper (1985) suggest that a common criterion in cluster selection is that the cluster solution explain at least $50 \%$ of the variance in each of the defining variables, which was only achieved by the 4-cluster solution for both parents (see Figs. 1 and 2 for 4-cluster solutions).

When comparing mothers' and fathers' 4-cluster solutions, very similar clusters emerged for both parents. Cluster 1 ( $n$ mother $=160,33 \%$; $n$ father $=131,38 \%)$ consisted of parents who reported relatively low levels of cocooning $(z$ mother $=-.36, z$ father $=-.58)$ and pre-arming $(z$ mother $=-1.05, z$ father $=-.90)$, and moderate levels of deference $(z$ mother $=.22, z$ father $=.56$ ). This cluster will be referred to as Actively Deferring Parents because for these parents, the decision to act in a deferring manner was an active choice of how to respond before misbehavior occurred. Cluster 2 ( $n$ mother $=67$, $14 \% ; n$ father $=46,14 \%$ ) consisted of parents who reported relatively low levels of cocooning $(z$ mother $=-.75, z$ father $=.27)$, but moderate to high levels of pre-arming $(z$ mother $=.55, z$ father $=.80)$ and deference $(z$ mother $=1.48, z$ father $=.98)$. This cluster will be referred to as Reasoned Deferring Parents because these parents balanced discussing concerns with their child with trusting the child to make independent decisions before misbehavior occurred. Cluster 3 ( $n$ mother $=104,21 \%$; $n$ father $=49,14 \%)$ consisted of parents who reported relatively low levels of cocooning $(z$ mother $=-.52, z$ father $=-.79)$ and deference $(z$ mother $=-.45, z$ father $=-.52)$, but relatively high levels of pre-arming $(z$ mother $=.73, z$ father $=.75)$. This cluster will be referred to as Pre-arming Parents because discussion or talking was the dominant strategy used by these parents before misbehavior occurred. Cluster $4(n$ mother $=157,32 \% ; n$ father $=115,34 \%)$ consisted of parents who reported relatively high levels of cocooning $(z$ mother $=1.05, z$ father $=.89)$, moderate levels of pre-arming $(z$ mother $=.37, z$ father $=.40$ ) and low levels of deference $(z$ mother $=-.57, z$ father $=-.80)$. This cluster will be referred to as Reasoned

Table 1

Correlations between all study variables.

\begin{tabular}{|c|c|c|c|c|c|c|c|c|c|c|c|c|c|c|}
\hline & 1 & 2 & 3 & 4 & 5 & 6 & 7 & 8 & 9 & 10 & 11 & 12 & 13 & 14 \\
\hline 1. Cocooning & - & $.22^{* * *}$ & $-.29 * * *$ & -.09 & .10 & .02 & .02 & $.12^{*}$ & $.15^{* *}$ & $-.19^{* * *}$ & .07 & .10 & .01 & -.06 \\
\hline 2. Pre-arming & $.13^{* *}$ & - & $-.18^{* * *}$ & .02 & .08 & $.15^{* *}$ & $.40^{* * *}$ & $.38^{* * *}$ & $.33^{* * *}$ & -.07 & $.13^{*}$ & .10 & $-.11^{*}$ & -.10 \\
\hline 3. Deference & $-.35^{* * *}$ & $-.19^{* * *}$ & - & -.05 & $-.22^{* * *}$ & -.03 & -.05 & -.02 & -.03 & .05 & -.09 & -.02 & .00 & .06 \\
\hline 4. Parental education & $-.15^{* * *}$ & -.05 & -.06 & - & .03 & $.18^{* * *}$ & .06 & .10 & .01 & -.04 & -.01 & .03 & $-.13^{*}$ & $-.17^{* *}$ \\
\hline 5. Parental religiosity & $.24^{* * *}$ & $.15^{* * *}$ & $-.12^{* *}$ & $-.15^{* * *}$ & - & -.01 & .05 & .02 & .11 & .01 & $.17^{* *}$ & $.12^{*}$ & .06 & .03 \\
\hline 6. Attachment (CR) & -.07 & $.11^{* *}$ & -.05 & .08 & $-.10^{*}$ & - & $.24^{* * *}$ & $.20^{* * *}$ & $.14^{* *}$ & -.02 & $.20^{* * *}$ & $.19^{* * *}$ & $-.28^{* * *}$ & $-.30^{* * *}$ \\
\hline 7. Connectedness & .02 & $.25^{* * *}$ & -.01 & .06 & -.01 & $.28^{* * *}$ & - & $.49^{* * *}$ & $.41^{* * * *}$ & $-.18^{* * *}$ & $.16^{* *}$ & .01 & $-.22^{* * *}$ & $-.18^{* * *}$ \\
\hline 8. Parental involvement (CR) & $.22^{* * *}$ & $.31^{* * *}$ & $-.16^{* *}$ & .05 & $.12^{*}$ & .08 & $.38^{* * *}$ & - & $.36^{* * *}$ & -.08 & $.17^{* *}$ & $.13^{*}$ & $-.20^{* * *}$ & $-.16^{* *}$ \\
\hline 9. Parental knowledge & $.09^{*}$ & $.17^{* * *}$ & $-.12^{* *}$ & $.12^{* *}$ & -.01 & $.14^{* * *}$ & $.24^{* * *}$ & $.31^{* * *}$ & - & $-.16^{* *}$ & .06 & .10 & $-.18^{* * *}$ & $-.18^{* * *}$ \\
\hline 10. Child age & $-.12^{* *}$ & .06 & $.18^{* * *}$ & $-.10^{*}$ & .01 & -.04 & -.02 & -.01 & $-.18^{* * *}$ & - & -.02 & -.04 & -.07 & $.23^{* * *}$ \\
\hline 11. Empathy & .03 & $.24^{* * *}$ & $-.13^{* *}$ & $.12^{* *}$ & .09 & $.18^{* * *}$ & $.36^{* * *}$ & $.28^{* * *}$ & $.11^{*}$ & -.02 & - & $.17^{* * *}$ & -.05 & $-.13^{* *}$ \\
\hline 12. Self-regulation (CR) & $.12^{* *}$ & $.11^{* *}$ & .02 & -.01 & .05 & $.25^{* * *}$ & $.15^{* * *}$ & .10 & .05 & -.04 & $.17^{* * *}$ & - & $-.12^{* *}$ & $-.13^{* *}$ \\
\hline 13. Internalizing behavior (CR) & .03 & $-.11^{* *}$ & -.01 & $-.12^{* *}$ & $.13^{* *}$ & $-.33^{* * *}$ & $-.14 * * *$ & -.03 & -.06 & -.07 & -.05 & $-.12^{* *}$ & - & $.32^{* * *}$ \\
\hline 14. Externalizing behavior (CR) & -.01 & -.08 & $.11^{* *}$ & $-.23^{* * *}$ & .04 & $-.28^{* * *}$ & $-.19^{* * *}$ & -.10 & $-.19^{* * *}$ & $.23^{* * *}$ & $-.13^{* *}$ & $-.13^{* *}$ & $.32^{* * *}$ & - \\
\hline
\end{tabular}

Note. Correlations for mothers are below the diagonal, correlations for fathers are above the diagonal. CR $=\mathrm{Child}$ Report.

${ }^{*} p<.05,{ }^{* *} p<.01,{ }^{* * *} p<.001$. 


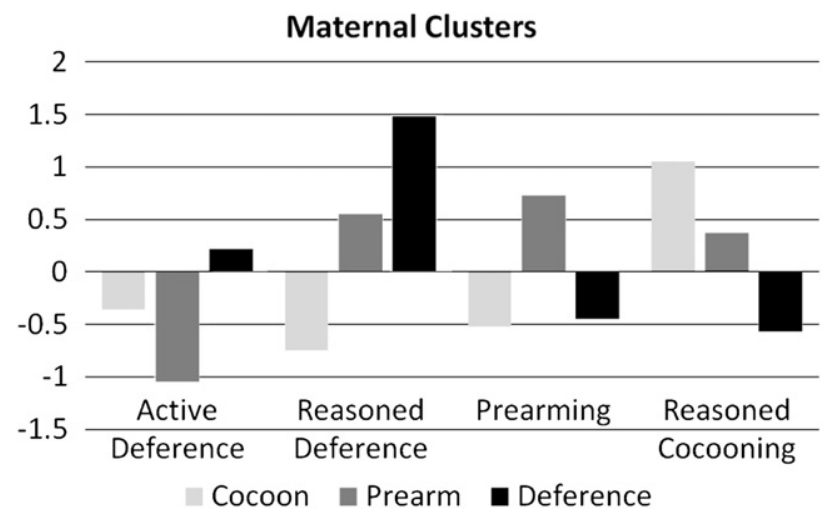

Fig. 1. Four-cluster proactive parenting solution for mothers.

Cocooning Parents because these parents largely sheltered their children from conflicting influences even before misbehavior occurred, but provided reasoning for those decisions.

\section{Differences as a function of cluster membership}

Differences as a function of cluster membership were assessed in three steps. First, we assessed demographics of the parent, including family structure, parental ethnicity, education, and religiosity. Second, we assessed the quality of the parent-child relationship, including parental attachment, connectedness, involvement, and knowledge. And finally, we assessed traits and behaviors of the child, including gender, age, empathy, self-regulation, and internalizing and externalizing behaviors.

\section{Demographics of the parent}

A chi-square analysis was conducted on the 4-cluster solution for mothers to determine if cluster membership differed as a function of family structure (single vs. two-parent family). Results revealed a significant difference between the four maternal clusters, $X^{2}(488)=7.91, p<.05$. Follow-up analyses revealed that the largest differences as a function of structure were with actively deferring parents (27\% of single-parents vs. $35 \%$ of two-parent families). There were minimal differences as a function of family structure for reasoned deference, pre-arming and reasoned cocooning mothers.

Another chi-square analysis was conducted on the 4-cluster solution for mothers and fathers to determine if cluster membership differed as a function of ethnicity of the parent. The chi-square was not significant for fathers, but was for mothers $X^{2}(488)=28.63, p<.001$. Follow-up analyses suggested that actively deferring was most common among European American mothers (36\% of EA, $20 \%$ of AA, 28\% of other), while reasoned cocooning was most common among African American and other minority parents (48\% AA, 43\% other, 28\% EA). Patterns also suggested that reasoned deferring was more common among African American mothers than either of the other groups (25\% of AA, $12 \%$ of EA, $13 \%$ of other) and that prearming was used the least by African American mothers (8\% AA, 25\% EA, 15\% other).

A number of univariate analyses of variance (ANOVAs) were conducted to determine if parental education and religiosity varied as a function of cluster membership (see Tables 2 and 3). For mothers, both of the two ANOVAs were statistically significant. Follow-up analyses suggested that actively deferring $(M=4.57)$ and pre-arming $(M=4.76)$ mothers reported higher levels of education than did reasoned deferring $(M=4.07)$ or reasoned cocooning $(M=4.17)$ mothers. In addition, reasoned cocooning mothers reported higher levels of religiosity $(M=3.15)$ than did actively deferring $(M=2.74)$, reasoned deferring $(M=2.74)$, or pre-arming $(M=2.76)$ mothers (who did not differ from one another). For fathers, the only significant ANOVA was in regard to religiosity, suggesting that reasoned cocooning fathers reported higher levels of religiosity $(M=2.78)$ than did actively deferring $(M=2.31)$ or reasoned deferring $(M=2.29)$ fathers (who did not differ from one another).

\section{Quality of the parent-child relationship}

Four univariate ANOVAs were conducted for each parent to determine if parental attachment, connectedness, involvement, and knowledge differed as a function of cluster membership (see Tables 2 and 3). For mothers, all four ANOVAs were statistically significant. Actively deferring $(M=4.07)$ mothers had lower levels of child-reported attachment than did pre$\operatorname{arming}(M=4.29)$ mothers. Actively deferring mothers $(M=4.77)$ reported lower levels of mother-child connectedness than did reasoned cocooning $(M=5.03)$, pre-arming $(M=5.07)$, and reasoned deferring $(M=5.14)$ mothers. Actively deferring $(M=3.98)$ mothers had lower levels of child-reported involvement than did reasoned deferring $(M=4.24)$, reasoned cocooning $(M=4.27)$, and pre-arming $(M=4.35)$ mothers. And finally, reasoned cocooning $(M=4.81)$ and pre-arming $(M=4.76)$ mothers reported higher levels of maternal knowledge than did actively deferring $(M=4.66)$ mothers.

For fathers, two of the four ANOVAs were statistically significant. Reasoned deferring $(M=5.09)$ fathers reported higher levels of father-child connectedness than did actively deferring $(M=4.57)$ and reasoned cocooning $(M=4.84)$ fathers. And 


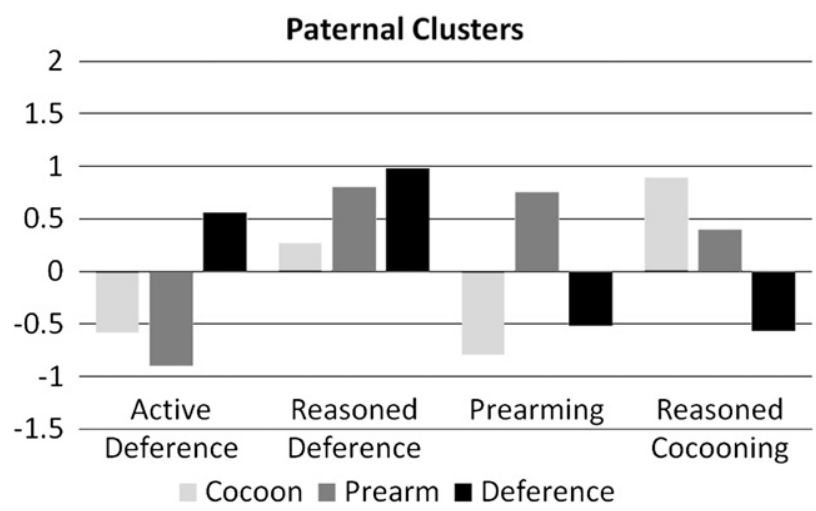

Fig. 2. Four-cluster proactive parenting solution for fathers.

actively deferring $(M=4.43)$ fathers reported lower levels of paternal knowledge than did pre-arming $(M=4.58)$, reasoned cocooning $(M=4.63)$, and reasoned deferring $(M=4.74)$ fathers.

Traits and behaviors of the child

A chi-square analysis was conducted for each parent to determine if gender of the child varied as a function of cluster membership, and it was not statistically significant for either parent. Five univariate ANOVAs were conducted for each parent to determine whether the child's age, empathy, self-regulation, internalizing behaviors, and externalizing behaviors varied as a function of cluster membership (see Tables 2 and 3). For mothers, four of the five ANOVAs were statistically significant. Actively deferring mothers had children with lower levels of empathy $(M=4.00)$ than did reasoned cocooning $(M=4.18)$, reasoned deferring $(M=4.21)$, or pre-arming $(M=4.32)$ mothers. Reasoned deferring $(M=3.20)$ and reasoned cocooning $(M=3.20)$ mothers had children with higher levels of self-regulation than did actively deferring $(M=3.01)$ mothers. Actively deferring $(M=6.59)$ mothers had children with higher levels of internalizing behaviors than did reasoned deferring $(M=4.67)$ or pre-arming $(M=5.28)$ mothers. And pre-arming $(M=.77)$ mothers had children with lower levels of externalizing behaviors than did actively deferring $(M=1.35)$ and reasoned deferring $(M=1.36)$ mothers.

For fathers, two of the five ANOVAs were statistically significant. Actively deferring $(M=11.39)$ fathers had older children than did reasoned deferring $(M=10.38)$ and reasoned cocooning $(M=11.10)$ fathers. And actively deferring fathers $(M=2.96)$ had children with lower levels of self-regulation than did reasoned deferring $(M=3.20)$ or reasoned cocooning $(M=3.18)$ fathers.

\section{Discussion}

The purpose of the current study was to explore whether proactive parenting practices clustered in meaningful ways, and to examine how the clusters that emerged might differ as a function of demographics of the parent, the quality of the parentchild relationship, and the traits and behaviors of the adolescent child. Findings suggested that there were four clusters that

Table 2

Mean differences as a function of mothers' cluster membership.

\begin{tabular}{|c|c|c|c|c|c|}
\hline \multirow[t]{2}{*}{ Variables } & Cluster 1 & Cluster 2 & Cluster 3 & Cluster 4 & $F$-test \\
\hline & Active deference & Reasoned deference & Pre-arming & Reasoned cocooning & $d f(3,484)$ \\
\hline Characteristics of the parent & $M(S D)$ & $M(S D)$ & $M(S D)$ & $M(S D)$ & \\
\hline Education & $4.57(1.52)^{a}$ & $4.07(1.51)^{\mathrm{b}}$ & $4.76(1.27)^{\mathrm{a}}$ & $4.17(1.67)^{\mathrm{b}}$ & $4.85^{* *}$ \\
\hline Religiosity & $2.74(1.01)^{\mathrm{a}}$ & $2.74(1.11)^{\mathrm{a}}$ & $2.76(1.00)^{a}$ & $3.15(.85)^{\mathrm{b}}$ & $6.25^{* * *}$ \\
\hline \multicolumn{6}{|c|}{ Characteristics of the parent-child relationship } \\
\hline Parental attachment (CR) & $4.07(.61)^{a}$ & $4.21(.50)^{\mathrm{ab}}$ & $4.29(.45)^{\mathrm{b}}$ & $4.19(.55)^{\mathrm{ab}}$ & $3.62^{* *}$ \\
\hline Parental connectedness & $4.77(.65)^{\mathrm{a}}$ & $5.14(.49)^{\mathrm{b}}$ & $5.07(.49)^{\mathrm{b}}$ & $5.03(.58)^{b}$ & $10.18^{* * *}$ \\
\hline Parental involvement (CR) & $3.98(.71)^{a}$ & $4.24(.54)^{b}$ & $4.35(.44)^{\mathrm{b}}$ & $4.27(.59)^{b}$ & $10.31^{* * *}$ \\
\hline Parental knowledge & $4.66(.41)^{\mathrm{a}}$ & $4.71(.37)^{\mathrm{ab}}$ & $4.76(.33)^{b}$ & $4.81(.30)^{\mathrm{b}}$ & $4.89^{* *}$ \\
\hline \multicolumn{6}{|l|}{ Characteristics of the child } \\
\hline Age & $11.27(1.04)$ & $11.54(1.08)^{\mathrm{a}}$ & $11.30(1.03)$ & $11.19(.93)^{\mathrm{b}}$ & 1.87 \\
\hline Empathy & $4.00(.58)^{\mathrm{a}}$ & $4.21(.56)^{b}$ & $4.32(.65)^{\mathrm{b}}$ & $4.18(.57)^{\mathrm{b}}$ & $6.82^{* * *}$ \\
\hline Self-regulation (CR) & $3.01(.66)^{\mathrm{a}}$ & $3.20(.59)^{\mathrm{b}}$ & $3.09(.61)^{\mathrm{ab}}$ & $3.20(.68)^{b}$ & $2.72^{*}$ \\
\hline Internalizing behaviors (CR) & $6.59(5.48)^{\mathrm{a}}$ & $4.67(3.76)^{b}$ & $5.28(4.39)^{\mathrm{b}}$ & $5.56(4.75)^{\mathrm{ab}}$ & $3.17^{*}$ \\
\hline Externalizing behaviors (CR) & $1.35(2.08)^{\mathrm{a}}$ & $1.36(2.06)^{a}$ & $.77(1.13)^{b}$ & $1.06(1.54)^{\mathrm{ab}}$ & $2.79^{*}$ \\
\hline
\end{tabular}

Note. Means with differing letters are significantly different from one another based on LSD post-hoc analyses. CR $=$ child report.

${ }^{*} p<.05 ;{ }^{* *} p<.01 ;{ }^{* * *} p<.001$. 
Table 3

Mean differences as a function of fathers' cluster membership.

\begin{tabular}{|c|c|c|c|c|c|}
\hline \multirow[t]{2}{*}{ Variables } & Cluster 1 & Cluster 2 & Cluster 3 & Cluster 4 & $F$-test \\
\hline & Active deference & Reasoned deference & Pre-arming & Reasoned cocooning & $d f(3,337)$ \\
\hline Characteristics of the parent & $M(S D)$ & $M(S D)$ & $M(S D)$ & $M(S D)$ & \\
\hline Education & $4.80(1.53)$ & $4.63(1.44)$ & $5.04(1.43)$ & $4.72(1.54$ & .71 \\
\hline Religiosity & $2.31(1.06)^{\mathrm{a}}$ & $2.29(1.07)^{\mathrm{a}}$ & $2.59(1.15)^{\mathrm{ab}}$ & $2.78(1.01)^{\mathrm{b}}$ & $4.80^{* *}$ \\
\hline \multicolumn{6}{|c|}{ Characteristics of the parent-child relationship } \\
\hline Parental attachment (CR) & $4.08(.58)$ & $4.20(.46)$ & $4.25(.39)$ & $4.16(.50)$ & 1.45 \\
\hline Parental connectedness & $4.57(.81)^{\mathrm{a}}$ & $5.09(.42)^{\mathrm{b}}$ & $4.98(.43)^{\mathrm{bc}}$ & $4.84(.68)^{c}$ & $8.89^{* * *}$ \\
\hline Parental involvement (CR) & $3.99(.73)^{\mathrm{a}}$ & $4.22(.54)^{\mathrm{b}}$ & $4.15(.48)^{\mathrm{ab}}$ & $4.13(.61)^{\mathrm{ab}}$ & 2.07 \\
\hline Parental knowledge & $4.43(.49)^{\mathrm{a}}$ & $4.74(.33)^{b}$ & $4.58(.37)^{\mathrm{b}}$ & $4.63(.39)^{\mathrm{b}}$ & $8.37^{* * *}$ \\
\hline \multicolumn{6}{|l|}{ Characteristics of the child } \\
\hline Age & $11.39(1.06)^{\mathrm{a}}$ & $10.98(.83)^{\mathrm{bc}}$ & $11.30(.97)^{\mathrm{abc}}$ & $11.10(.87)^{\mathrm{bc}}$ & $3.11^{*}$ \\
\hline Empathy & $4.11(.61)^{a}$ & $4.16(.68)^{\mathrm{ab}}$ & $4.25(.54)^{\mathrm{ab}}$ & $4.26(.52)^{\mathrm{b}}$ & 1.49 \\
\hline Self-regulation (CR) & $2.96(.61)^{\mathrm{a}}$ & $3.20(.57)^{\mathrm{b}}$ & $3.16(.57)^{\mathrm{ab}}$ & $3.18(.62)^{\mathrm{b}}$ & $3.42^{*}$ \\
\hline Internalizing behaviors (CR) & $5.87(5.11)$ & $5.07(4.23)$ & $5.73(3.95)$ & $5.89(5.19)$ & .36 \\
\hline Externalizing behaviors (CR) & $.95(1.34)$ & $.70(.96)$ & $.84(1.09)$ & $.88(1.66)$ & .41 \\
\hline
\end{tabular}

Note. Means with differing letters are significantly different from one another based on LSD post-hoc analyses. CR $=$ child report.

${ }^{*} p<.05,{ }^{* *} p<.01,{ }^{* * *} p<.001$.

were similar across both mothers and fathers, which we termed active deference (predominantly deference), reasoned deference (deference and pre-arming), pre-arming (predominantly pre-arming), and reasoned cocooning (pre-arming and cocooning). Active deference and reasoned cocooning were the most commonly used proactive approaches for both mothers and fathers. The emergence of these clusters is consistent with research on reactive parenting practices, suggesting that parents do not necessarily use one predominant strategy across situations (Grusec \& Goodnow, 1994; Grusec \& Kuczynski, 1980). These findings also add to existing knowledge by suggesting that parental flexibility occurs with proactive parenting practices as well. Indeed, taking a typological approach more accurately represents parent-child interactions by recognizing that individual parenting practices often occur in conjunction with other practices, which may change the positive or deleterious effect of the practice when used in isolation (Darling \& Cumsille, 2003).

\section{Active deference}

Given that research has found a neglectful parenting style to be among the most common in the United States (Steinberg, Lamborn, Darling, Mounts, \& Dornbusch, 1994), it is perhaps not entirely surprising that $1 / 3$ of mothers and nearly $40 \%$ of fathers in the current study were characterized as being actively deferring. Parents who used active deference were doing little to protect their adolescents from potentially conflicting sources of values, and although this may have been in an attempt to promote autonomy, results suggested that this may not be the most adaptive parental approach for early adolescents. In terms of demographics of the parent, active deference was proportionally more common in two-parent families, among European American mothers, and among highly educated mothers. It is possible that parents who have more resources (whether in the form of a co-parent, or resources that come with education) may overestimate their ability to socialize and protect their children, resulting in practices with high levels of autonomy, which may not be developmentally appropriate for early adolescents. This possibility is consistent with research suggesting that there is a propensity for highly affluent families to fail to engage in appropriate reactive parenting (Luthar \& Latendresse, 2005), and suggests that relative affluence may also be related to a failure to use appropriate proactive parenting practices. Future research should more carefully examine this possibility.

Findings also suggested that actively deferring mothers and fathers had the lowest levels of parental monitoring, and that actively deferring mothers had the lowest levels of connectedness, involvement, and attachment. Further, especially for mothers, using proactive deference was indicative of adolescents who had the lowest levels of empathy and self-regulation, and the highest levels of internalizing and externalizing problems. Although bivariate correlations did not paint quite as bleak a picture for parents' use of deference, it appears that while parents may perceive their actions to be "active," using deference as the primary proactive response may be more indicative of permissiveness. Indeed, it may be that parents who use proactive deference in a developmentally inappropriate way (i.e., with children who are not developmentally prepared for complete autonomy), may also be parents who are misjudging the importance of parental involvement in response to adolescents' transgressions. Future research should examine whether using active deference during later adolescence or emerging adulthood is associated with higher quality parenting and more positive child outcomes. Given that older adolescents' demands for autonomy are heightened (Steinberg, 2001), and that parental values may have been well communicated and established by this point, active deference may be appropriate at later developmental ages. Taken together, it seems that determining when the use of active deference is appropriate (i.e., determining which parental rules have been accurately perceived and accepted; Grusec \& Goodnow, 1994), may be an important aspect of effective proactive parenting. 
Although active deference appears to be a relatively ineffective approach to proactive parenting during early adolescence, results suggested that reasoned deference (or relatively high levels of deference combined with pre-arming) was relatively more adaptive. More specifically, reasoned deference did not differ significantly from pre-arming and reasoned cocooning in terms of a positive parent-child relationship, and parents who used reasoned deference had higher levels of connection, involvement, and knowledge (the latter for fathers only) than did actively deferring parents. In addition, parents (primarily mothers) who used reasoned deference had children with higher levels of empathy and self-regulation, and lower levels of internalizing behavior than children whose parents used active deference. This suggests that as children enter adolescence, talking to them and then allowing them to make their own decision may provide an appropriate balance between communication of parental socialization values and adolescents' trust and need for autonomy. These findings also highlight the importance of a cluster approach to studying parenting, which should be applied to both reactive and proactive parenting practices (Darling \& Cumsille, 2003). Although one parenting practice in isolation may be ineffective (e.g., deference or power assertion), it is valuable to know how individual parenting practices function in the context of other parenting practices, especially considering the conceptual and statistical power inherent in typological analyses.

\section{Prearming}

Consistent with research highlighting the importance of reasoning with children after a misdeed (Hoffman, 1994; Krevans \& Gibbs, 1996), and research on the importance of parent-child communication (Laursen \& Collins, 2004), mothers who consistently used pre-arming had adolescents with the lowest levels of externalizing behavior. Further, bivariate correlations suggested that pre-arming was the most consistently related to positive child outcomes for both mothers and fathers. Taken together, these findings suggest that both proactive and reactive parenting practices that maximize open communication are effective forms of socialization, which is likely due to adolescents' ability to accurately perceive parental values messages when they are communicated in a clear, developmentally appropriate fashion (Grusec \& Goodnow, 1994). Just as research on reactive parenting practices has called for attention to be paid to the different forms of induction and power assertion (Grusec \& Goodnow, 1994), future research should examine different forms of proactive parenting practices, especially the different forms of pre-arming; such as talking, warning, threatening, and making fun of or making derogatory comments about those who are acting contrary to parental values (Barr \& Neville, 2008; Gardner et al., 2007; Harrison, Wilson, Pine, \& Chan, 1990). It is possible that different approaches to pre-arming are more effective than others, and that the content, quality, and affect of parents' pre-arming attempts are all important in determining effectiveness.

\section{Reasoned cocooning}

Reasoned cocooning was the most controlling approach to proactive parenting in the current study, as cocooning is generally a parent's attempt to prevent adolescents' exposure to conflicting values before misbehavior can occur. Findings suggested that reasoned cocooning was used by nearly 50\% of African American mothers, which is consistent with research examining reactive discipline among minority parents (Smetana \& Daddis, 2002). Findings also suggested that reasoned cocooning was more common for both mothers and fathers who were highly religious, which is consistent with research suggesting that parents who are religious use more active strategies (i.e., pre-arming and cocooning) in an attempt to teach their beliefs and values (Padilla-Walker \& Thompson, 2005). It is possible that parents who feel a lack of support from the surrounding community, perhaps due to conservative or unique socialization goals, feel greater threat to their values and thus use increased levels of control. It is also possible that parental goals vary as a function of family structure, ethnicity, education, and level of religiosity. This is consistent with Darling and Steinberg's (1993) notion that different parental goals lead to different parenting practices, which may account for differences in the effectiveness of particular parenting styles. Given research suggesting that parental goals are the strongest and most consistent predictor of proactive parenting practices (Padilla-Walker, 2006), future research should continue to examine parental goals, motivations, and beliefs behind particular proactive practices.

In terms of adolescent outcomes, just as parental power assertion often results in negative emotional responses from adolescents (Padilla-Walker, 2008), it is possible that cocooning without explanation not only results in frustration from the child, but also does not allow for communication of parental values. However, evidence of reasoned cocooning being consistently negative was not present, possibly because cocooning was coupled with pre-arming, which may help the adolescent to understand and accept parental values despite a less autonomous approach. Bivariate correlations did suggest that cocooning was less common among older adolescents, and future research should examine the effectiveness of proactive control developmentally. Just as active deference may not be developmentally appropriate for early adolescents, cocooning may not be developmentally appropriate for older adolescents who are generally not as accepting of parental authority. Future research should also more carefully examine the effectiveness of proactive parenting as a function of ethnicity and religiosity, as it is possible that controlling parenting may not be as negative for some groups as it is for others (Steinberg, 2001). 


\section{Limitations and conclusions}

The primary limitation of the current study was that findings were not reported from the strength of a longitudinal design, so it was impossible for us to determine direction of effects. Future research is necessary to better establish the bidirectionality of proactive parenting practices, as particular child traits and behaviors may elicit or be more conducive to, for example, proactive control. The current measure of proactive parenting also had a limited number of items, which was particularly problematic for the cocooning scale. Although the alphas for cocooning were relatively low, internal consistency of scales is highly dependent upon length. The correlation between the two cocooning items was $>.25$, which is typical for many well-used scales. Factor analysis gave us confidence that these items were tapping the same aspect of parenting, although well-established scales of proactive parenting are needed. Further contributing to this issue, our measure of proactive parenting was limited in that it collapsed across parenting behavior in response to both peers and media. Although not expressly assessing proactive parenting practices, research on parental management of peers (Mounts, 2002) and media use (Nikken \& Jansz, 2006) suggests that the content of proactive parenting practices may vary as a function of the context (e.g., peers vs. media; Padilla-Walker, 2006). This is also consistent with reactive parenting practices that have been found to be domain specific, which may explain why we would not necessarily expect cocooning toward peers and media to be more strongly related, despite the similar levels of control inherent in this proactive practice.

Despite these limitations, the current study adds to our knowledge of parenting practices by highlighting the importance of proactive parenting not only during early childhood (Gardner et al., 2007; Holden, 1983; Holden \& West, 1989), but during adolescence as well. Findings identified four proactive parenting clusters that were consistent across both mothers and fathers, and suggested that proactive parenting practices varied primarily as a function of the demographics of the parent and the traits and behaviors of the adolescent child. This study places particular emphasis on parents' use of multiple proactive strategies, especially highlighting the role of pre-arming (either alone or in combination with other strategies) as an effective means of communicating parental beliefs and values in an attempt to avoid misbehavior before it occurs. Building on past research that has suggested important distinctions between parenting styles and parenting practices (Darling \& Steinberg, 1993), the current study calls for continued research that clearly distinguishes between reactive and proactive parenting practices.

\section{Acknowledgements}

We thank the Family Studies Center at BYU, the School of Family Life, and the College of Family Home and Social Science at BYU, and we recognize the generous support of the many private donors who provided support for this project. We also thank those families who were willing to spend valuable hours with our team in interviews, and the many students who assisted in conducting the interviews.

\section{References}

Armsden, G., \& Greenberg, M. (1987, October). The inventory of parent and peer attachment: individual differences and their relationship to psychological well-being in adolescence. Journal of Youth and Adolescence, 16(5), 427-454.

Barber, B. K., Stolz, H. E., Olsen, J. A., \& Maughn, S. L. (2005). Parental support, psychological control, and behavioral control: assessing relevance across time, culture, and method. Monographs of the Society for Research in Child Development, 70(4).

Barr, S. C., \& Neville, H. A. (2008). Examination of the link between parental racial socialization messages and racial ideology among black college students. Journal of Black Psychology, 34(2), 131-155.

Bergman, L. R., Magnusson, D., \& El-Khouri, B. M. (2003). Studying individual development in an interindividual context: A person-oriented approach. Mahwah, NJ: Lawrence Erlbaum.

Bugental, D. B., \& Goodnow, J. J. (1998). Socialization processes. In N. Eisenberg, \& N. Eisenberg (Eds.), Handbook of child psychology (5th ed.).Social, emotional, and personality development, Vol. 3 (pp. 389-462) Hoboken, NJ US: John Wiley \& Sons Inc.

Coll, C. G., \& Pachter, L. M. (2002). Ethnic and minority parenting. In M. H. Bornstein (Ed.), Handbook of parenting: Vol. 4: Social conditions and applied parenting (2nd ed.). (pp. 1-20) Mahwah, NJ: Lawrence Erlbaum Associates.

Conger, R. D., \& Donnellan, M. B. (2007). An interactionist perspective on the socio-economic context of human development. Annual Review of Psychology, $58,175-199$.

Darling, N., \& Cumsille, P. (2003). Theory, measurement, and methods in the study of family influences on adolescent smoking. Addiction, 98, 21-36.

Darling, N., \& Steinberg, L. (1993). Parenting style as context: an integrative model. Psychological Bulletin, 113, 487-496.

Davis, M. H. (1983). The effects of dispositional empathy on emotional reactions and helping: a multidimensional approach. Journal of Personality, 51,167-184.

Denham, S. A., Workman, E., Cole, P. M., Weissbrod, C., Kendziora, K. T., \& Zahn-Waxler, C. (2000). Prediction of externalizing behavior problems from early to middle childhood: the role of parental socialization and emotion expression. Development and Psychopathology, 12(1), 23-45.

Eisenberg, N., \& Fabes, R. A. (1998). Prosocial development. In N. Eisenberg, \& N. Eisenberg (Eds.), Handbook of child psychology (5th ed.).Social, emotional, and personality development, Vol. 3 (pp. 701-778) Hoboken, NJ US: John Wiley \& Sons Inc.

Farrington, D. P. (2004). Conduct disorder, aggression, and delinquency. In R. M. Lerner, \& L. Steinberg (Eds.), Handbook of adolescent psychology (2nd ed.). (pp. 627-664) Hoboken, NJ: Wiley.

Gardner, F., Shaw, D. S., Dishion, T. J., Burton, J., \& Supplee, L. (2007). Randomized prevention trial for early conduct problems: effects on proactive parenting and links to toddler disruptive behavior. Journal of Family Psychology, 21(3), 398-406.

Gardner, F., Ward, S., Burton, J., \& Wilson, C. (2003). The role of mother-child joint play in the early development of children's conduct problems: a longitudinal observational study. Social Development, 12(3), 361-378.

Goodnow, J. J. (1997). Parenting and the transmission and internalization of values: from social-cultural perspectives to within-family analyses. In J. E. Grusec, L. Kuczynski, J. E. Grusec, \& L. Kuczynski (Eds.), Parenting and children's internalization of values: A handbook of contemporary theory (pp. 333361). Hoboken, NJ US: John Wiley \& Sons Inc.

Goodnow, J. J. (2002). Parents' knowledge and expectations: using what we know. In M. H. Bornstein, \& M. H. Bornstein (Eds.), Handbook of parenting (2nd ed.).Being and becoming a parent, Vol. 3 (pp. 439-460) Mahwah, NJ US: Lawrence Erlbaum Associates Publishers. 
Graber, J. A. (2004). Internalizing problems during adolescence. In R. M. Lerner, \& L. Steinberg (Eds.), Handbook of adolescent psychology (2nd ed.). (pp. 587626) Hoboken, NJ: Wiley.

Grusec, J. E. (2002). Parenting socialization and children's acquisition of values. In M. H. Bornstein, \& M. H. Bornstein (Eds.), Handbook of parenting (2nd ed. ).Practical issues in parenting, Vol. 5 (pp. 143-167) Mahwah, NJ US: Lawrence Erlbaum Associates Publishers.

Grusec, J. E., \& Goodnow, J. J. (1994). Impact of parental discipline methods on the child's internalization of values: a reconceptualization of current points of view. Developmental Psychology, 30(1), 4-19.

Grusec, J. E., \& Kuczynski, L. (1980). Direction of effect in socialization: a comparison of the parent's versus the child's behavior as determinants of disciplinary techniques. Developmental Psychology, 16, 1-9.

Hair, J. F., Jr., Anderson, R. E., Tatham, R. L., \& Black, W. C. (1998). Multivariate data analysis (5th ed.). Upper Saddle River, NJ: Prentice-Hall.

Harrison, A. O., Wilson, M. N., Pine, C. J., Chan, S. Q., \& Buriel, R. (1990). Family ecologies of ethnic minority children. Child Development, 61(2), 347-362.

Hawkins, A. J., Bradford, K. P., Palkovitz, R., Day, R. D., Christiansen, S. L., \& Call, V. C. (2002). The inventory of father involvement: a pilot study of a new measure of father involvement. Journal of Men's Studies, 10, 183-196.

Hawkins, J. D., Graham, J. W., Maguin, E., Abbott, R., Hill, K. G., \& Catalano, R. F. (1997). Exploring the effects of age alcohol use initiation and psychosocial risk factors on subsequent alcohol misuse. Journal of Studies on Alcohol, 58(3), 280-290.

Hoffman, M. L. (1994). Discipline and internalization. Developmental Psychology, 30, 26-28.

Holden, G. W. (1983). Avoiding conflict: mothers as tacticians in the supermarket. Child Development, 54(1), $233-240$.

Holden, G. W., \& West, M. J. (1989). Proximate regulation by mothers: a demonstration of how differing styles affect young children's behavior. Child Development, 60(1), 64-69.

Kerr, D. C. R., Lopez, N. L., Olson, S. L., \& Sameroff, A. J. (2004). Parental discipline and externalizing behavior problems in early childhood: the roles of moral regulation and child gender. Journal of Abnormal Child Psychology, 32(4), 369-383.

Kerr, M., \& Stattin, H. (2000). What parents know, how they know it, and several forms of adolescent adjustment: further support for a reinterpretation of monitoring. Developmental Psychology, 36, 366-380.

Kochanska, G., Aksan, N., Knaack, A., \& Rhines, H. M. (2004). Maternal parenting and children's conscience: early security as moderator. Child Development, $75,1229-1242$.

Kosterman, R., Hawkins, J. D., Guo, J., Catalano, R. F., \& Abbott, R. D. (2000). The dynamics of alcohol and marijuana initiation: patterns and predictors of first use in adolescence. American Journal of Public Health, 90(3), 360-366.

Krevans, J., \& Gibbs, J. C. (1996). Parents' use of inductive discipline: relations to children's empathy and prosocial behavior. Child Development, 67, 32633277.

Ladd, G. W., \& Pettit, G. S. (2002). Parenting and the development of children's peer relationships. In M. H. Bornstein (Ed.), Handbook of parenting (2nd ed. ).Practical issues in parenting, Vol. 5 (pp. 269-309) Mahwah, NJ: Lawrence Erlbaum Associates.

Lansford, J. E., Malone, P. S., Stevens, K. I., Dodge, K. A., Bates, J. E., \& Pettit, G. S. (2006). Developmental trajectories of externalizing and internalizing behaviors: factors underlying resilience in physically abused children. Development and Psychopathology, 18(1), 35-55.

Laursen, B., \& Collins, W. A. (2004). Parent-child communication during adolescence. In A. L. Vangelisti (Ed.), Handbook of family communication (pp. 333348). Mahwah, NJ: Lawrence Erlbaum.

Lee, R. M., Draper, M., \& Lee, S. (2001). Social connectedness, dysfunctional interpersonal behaviors, and psychological distress: testing a mediator model. Journal of Counseling Psychology, 48, 310-318.

Letiecq, B. L. (2007). African American fathering in violent neighborhoods: what role does spirituality play? Fathering, 5(2), 111-128.

Lewis, C. A., Shevlin, M., McGuckin, C., \& Navrtil, M. (2001). The Santa Clara strength of religious faith questionnaire: confirmatory factor analysis. Pastoral Psychology, 49, 379-384.

Luthar, S. S., \& Latendresse, S. J. (2005). Children of the affluent: challenges to well-being. Current Directions in Psychological Science, 14, 49-53.

Maccoby, E. E. (2007). Historical overview of socialization research and theory. In J. E. Grusec, P. D. Hastings, J. E. Grusec, \& P. D. Hastings (Eds.), Handbook of socialization: Theory and research (pp. 13-41). New York, NY US: Guilford Press.

Milligan, G. W., \& Cooper, M. C. (1985). An examination of procedures determining the number of clusters in a data set. Psychometrika, 50, 159-179.

Mounts, N. S. (2002). Parental management of adolescent peer relationships in context: the role of parenting style. Journal of Family Psychology, 16, 58-69.

Nikken, P., \& Jansz, J. (2006). Parental mediation of children's videogame playing: a comparison of the reports by parents and children. Learning, Media and Technology, 31, 181-202.

Novak, S. P., \& Clayton, R. R. (2001). The influence of school environment and self-regulation on transitions between stages of cigarette smoking: a multilevel analysis. Health Psychology, 20, 196-207.

Padilla-Walker, L. M. (2006). “Peers I can monitor, it's media that really worries me!” Parental cognitions as predictors of proactive parental strategy choice. Journal of Adolescent Research, 21(1), 56-82.

Padilla-Walker, L. M. (2008). "My mom makes me so angry!" Adolescent perceptions of mother-child interactions as determinants of adolescent emotions. Social Development, 17, 306-325.

Padilla-Walker, L. M., \& Thompson, R. A. (2005). Combating conflicting messages of values: a closer look at parental strategies. Social Development, 14(2), 305-323.

Pettit, G. S., Keiley, M. K., Laird, R. D., Bates, J. E., \& Dodge, K. A. (2007). Predicting the developmental course of mother-reported monitoring across childhood and adolescence from early proactive parenting, child temperament, and parents' worries. Journal of Family Psychology, 21(2), 206-217.

Pettit, G. S., Laird, R. D., Dodge, K. A., Bates, J. E., \& Criss, M. M. (2001). Antecedents and behavior-problem outcomes of parental monitoring and psychological control in early adolescence. Child Development, 72(2), 583-598.

Putnam, S. P., Spritz, B. L., \& Stifter, C. A. (2002). Mother-child coregulation during delay of gratification at 30 months. Infancy, 3(2), $209-225$.

Smetana, J. G., \& Daddis, C. (2002). Domain-specific antecedents of parental psychological control and monitoring: the role of parenting beliefs and practices. Child Development, 73(2), 563-580.

Steinberg, L. (2001). We know some things: parent-adolescent relationships in retrospect and prospect. Journal of Research on Adolescence, 11(1), 1-19.

Steinberg, L., Lamborn, S. D., Darling, N., Mounts, N. S., \& Dornbusch, S. M. (1994). Over-time changes in adjustment and competence among adolescents from authoritative, authoritarian, indulgent, and neglectful families. Child Development, 65, 754-770.

Steinberg, L., \& Silk, J. S. (2002). Parenting adolescents. In M. H. Bornstein (Ed.), Handbook of parenting (2nd ed.).Children and parenting, Vol. 1 (pp. 103-133) Mahwah, NJ: Lawrence Erlbaum Associates.

Ward, J. H. (1963). Hierarchical grouping to optimize an objective function. Journal of the American Statistical Association, 58, $236-244$.

Weinraub, M., Horvath, D. L., \& Gringlas, M. B. (2002). Single parenthood. In M. H. Bornstein (Ed.), Handbook of parenting (2nd ed.).Being and becoming a parent, Vol. 3 (pp. 109-140) Mahwah, NJ: Lawrence Erlbaum Associates. 